\title{
INFLUENT TEMPERATURE EFFECTS ON THE ACTIVATED SLUDGE PROCESS AT A MUNICIPAL WASTEATER TREATMENT PLANT
}

\author{
MARIUS-ADRIAN BREHAR ${ }^{a}$, MELINDA VÁRHELY|a,*, \\ VASILE-MIRCEA CRISTEA ${ }^{a}$, DANIEL CRÎSTIUa, \\ ȘERBAN-PAUL AGACHI ${ }^{a}$
}

\begin{abstract}
The influent temperature has an important effect on the activated sludge process at the municipal Wastewater Treatment Plants (WWTPs). This research is associated to a case study of a Romanian municipal WWTP with Anaerobic-Anoxic-Aerobic $\left(A^{2} O\right)$ layout. Based on mathematical modelling it was studied the influent wastewater temperature effect on the effluent components concentration and on the concentration of pollutants and biomass concentrations at the outlet of biodegradation basins aerobic zone. Three influent temperature profiles were considered and implemented in the simulator. They reveal the representative 22 days period of the months: February (coldest water season), May (intermediate season) and July (warmest season). The simulations were performed both in steady and dynamic state. It was observed that higher influent temperatures intensify the nitrification and denitrification processes. As a result, the concentration of the nitrogen compounds in the effluent and at the end of the bioreactors decreases with the increase of the temperature. The carbon rich organic components feature a minor increase in the effluent. The study reveals that short time daily influent temperature changes do not have significant effect on the effluent components concentration, but the long-term ones affect the WWTP performance.
\end{abstract}

Keywords: wastewater treatment, mathematical modelling, Activated Sludge Model No. 1, Benchmark Simulation Model No. 1, influent temperature effects

\footnotetext{
a Babeş-Bolyai University, Faculty of Chemistry and Chemical Engineering, 11 Arany Janos str., RO-400028, Cluj-Napoca, Romania

*Corresponding author e-mail: mvarhelyi@chem.ubbcluj.ro
} 


\section{INTRODUCTION}

Wastewater Treatment Plants (WWTPs) reproduce in an intensified way the biodegradation processes that naturally occur in rivers, lakes and other natural water systems [1]. The most versatile and effective of all wastewater treatment processes and the most commonly used system for the treatment of municipal wastewater is the activated sludge process. Nitrification and denitrification are the two major parts of the activated sludge process together with the carbon and phosphorus transformations [2]. Microorganisms are used to degrade and to remove the pollutants from the sewage network originating wastewater.

Research in the field of wastewater treatment has largely gained importance during the past years. Usually, limited reliable online measurements for process monitoring and process control at full-scale WWTPs are available and, as a result, complex mathematical models have been constantly developed. The Activated Sludge Models (ASMs) describe the carbon, nitrogen and phosphorus removal, whereas the Benchmark Simulation Models (BSMs) also add the sedimentation process model. Mathematical models are used for the study of the complex activated sludge process, for the evaluation of different influential factors' effects on plant performance and for the implementation of advanced control algorithms $[3,4]$. A calibrated WWTP simulator has become a very valuable tool for analyzing the internal processes taking place at the WWTPs and finding solutions to process control or to operating problems $[5,6]$.

Temperature has a significant influence on the growth of autotrophic microorganisms and plays an important role in the nitrification process. The development of the heterotrophic biomass is also dependent on the temperature of wastewater [7]. Influent wastewater temperature depends on a series of factors such as: ambient temperature, architecture of the sewer system and the weather events (e.g. rain, storm, snow). In the context of climate change, significant temperature changes can be expected influencing accordingly the influent wastewater temperature. Advanced control algorithms, such as model predictive control, may be an efficient solution for the efficient management of WWTPs, but the effect of temperature needs to be investigated as it is an important predictable disturbance. Noteworthy, potential heat recovery can be achieved from the sewage water but this requires an assessment of influent temperature effect on the operation of the WWTP [8].

This paper presents the investigation of the influent temperature effects on the concentration of pollutants in the WWTP effluent and at the outlet of the biodegradation tanks. Based on steady and dynamic state 
mathematical modelling and simulation results, the analysis is performed by considering different influent temperature profiles measured at the WWTP inlet, covering both short-time and long-time temperature changes.

\section{MODEL DESCRIPTION AND CALIBRATION}

The dynamic municipal WWTP simulator used in the present study is describing an $A^{2} O$ (Anaerobic-Anoxic-Oxic) plant layout, presented in Figure 1. The WWTP simulator is based on the Activated Sludge Model No. 1 (ASM1) presented by Henze et al and the COST/IWA Benchmark Simulation Model No. 1 (BSM1) [9]. The model includes a primary settler, five bioreactors and a secondary clarifier. The primary settler is based on the Otterpohl and Freund model and describes the partial removal of particulate pollutants from the raw wastewater. The five bioreactors are connected in series. The first bioreactor is an anaerobic bioreactor. It receives the wastewater leaving the primary settler and the return activated sludge recycle stream (external recirculation). The second bioreactor is an anoxic one and has the main role in the denitrification process. It processes the wastewater collected from the anaerobic part of the biodegradation basins and the nitrate recirculation stream (internal recirculation). The last three bioreactors are aerated bioreactors where the nitrification process takes place. According to ASM1, the biodegradation processes consider two types of microorganisms: heterotrophs and autotrophs [10]. Basically, 8 main biochemical processes and the behavior of 13 different compounds (state variables) are described by a set of non-linear mass conservation and constitutive differential equations. The secondary settler is based on the settler model of Takács et al, which considers the settling velocity being described as a double-exponential function [11].

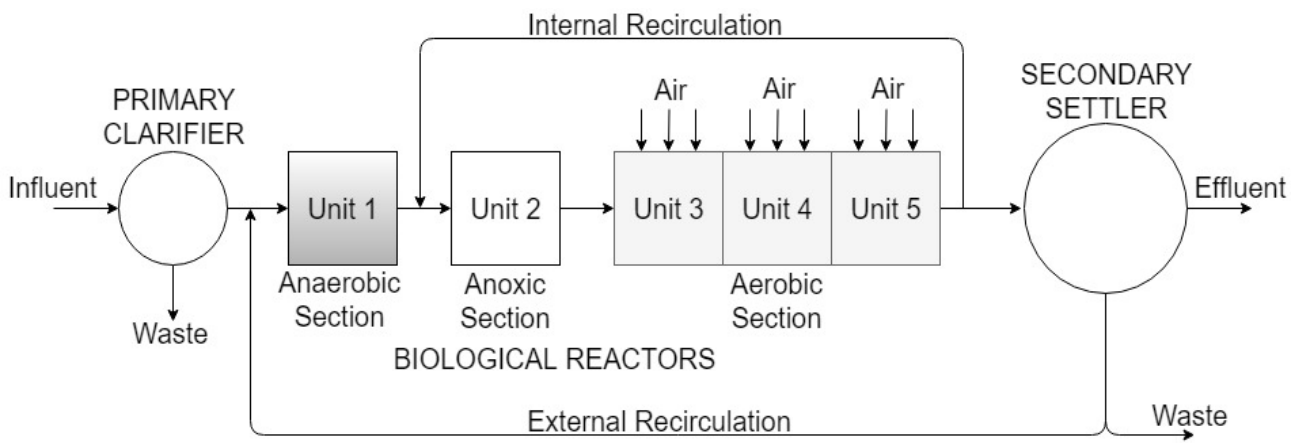

Figure 1. The $A^{2} O$ configuration of the investigated municipal WWTP 
The calibration of the WWTP simulator was accomplished using data from the online Supervisory Control and Data Acquisition (SCADA) system and laboratory measured influent and effluent data. The flow rates of the recycle streams and the air entering the aerobic biodegradation tanks, associated to the plant configuration, dimensions and characteristics of equipment collected from the studied municipal WWTP were included in the calibrated simulator. The model was calibrated with the dynamic and average data collected during the month May 2016, taking into consideration the first 22 days of this month. A set of influent variables, combined with a few of process and settler parameters, were determined using steady state Pareto multiobjective optimization. The WWTP model calibrated in steady state was also evaluated in dynamic state with measured data at every 10 minutes, showing a good fit between the simulated and measured effluent data. The calibration was accomplished successfully and the calibrated dynamic WWTP was used in the present research.

\section{RESULTS AND DISCUSSION}

The effects of the influent wastewater temperature on the biomass composition and the effluent quality indicators were investigated with the calibrated simulator. In the warm season the cellular activity of microorganisms is intensified. It is also known from the WWTP process work that in the cold season the aeration processes are intensified, as the dissolved oxygen concentration in the bioreactor decreases when temperature increases. These main effects are demonstrated by practice operation data. Analysis and interpretations of the influent temperature effects have been made based on both steady state and dynamic WWTP behavior.

\section{Influent Temperature Effects - Steady State}

The model was calibrated with the influent temperature of $15.83^{\circ} \mathrm{C}$, i.e. the average influent temperature of the WWTP measured data during the intermediate season (May month). After calibration, five new steady state simulations were run, in which the mentioned average temperature was replaced with the following new influent temperature values: $10^{\circ} \mathrm{C}, 13^{\circ} \mathrm{C}, 16^{\circ} \mathrm{C}$, $19^{\circ} \mathrm{C}$ and $22^{\circ} \mathrm{C}$. Both the influent temperature and influent concentrations were considered constant, until steady state was obtained. The results of the steady state simulations are presented in Table 1, for the wastewater leaving the aerated section and for the secondary setter effluent. 
INFLUENT TEMPERATURE EFFECTS ON THE ACTIVATED SLUDGE PROCESS AT A MUNICIPAL ...

Table 1. The influent temperature effects in steady state

\begin{tabular}{|c|c|c|c|c|c|c|}
\hline \multirow[t]{2}{*}{ Variable } & \multirow[t]{2}{*}{ Notation } & \multicolumn{5}{|c|}{ Temperature } \\
\hline & & $10^{\circ} \mathrm{C}$ & $13^{\circ} \mathrm{C}$ & $16^{\circ} \mathrm{C}$ & $19^{\circ} \mathrm{C}$ & $22^{\circ} \mathrm{C}$ \\
\hline \multicolumn{7}{|l|}{ Aerated section - Unit 5} \\
\hline $\begin{array}{l}\text { Readily biodegradable } \\
\text { substrate }\left[\mathrm{g} \mathrm{COD} / \mathrm{m}^{3}\right]\end{array}$ & Ss & 1.02 & 1.03 & 1.06 & 1.08 & 1.11 \\
\hline $\begin{array}{l}\text { Slowly biodegradable } \\
\text { substrate }\left[\mathrm{g} \mathrm{COD} / \mathrm{m}^{3}\right]\end{array}$ & $\mathrm{X}_{\mathrm{s}}$ & 46.55 & 47.23 & 48.46 & 49.74 & 51.00 \\
\hline $\begin{array}{l}\text { Heterotrophic biomass } \\
{\left[\mathrm{g} \text { COD } / \mathrm{m}^{3}\right]}\end{array}$ & $\mathrm{X}_{\mathrm{BH}}$ & 2080.11 & 2081.81 & 2082.59 & 2083.11 & 2083.50 \\
\hline $\begin{array}{l}\text { Autotrophic biomass } \\
\left.\text { [g COD/m } / \mathrm{m}^{3}\right]\end{array}$ & $\mathrm{X}_{\mathrm{BA}}$ & 114.46 & 119.23 & 120.64 & 121.29 & 121.76 \\
\hline $\begin{array}{l}\text { Dissolved oxygen } \\
{\left[\mathrm{g} \mathrm{O}_{2} / \mathrm{m}^{3}\right]}\end{array}$ & So & 4.19 & 4.45 & 4.56 & 4.53 & 4.44 \\
\hline $\begin{array}{l}\text { Nitrate and nitrite nitrogen } \\
{\left[\mathrm{g} \mathrm{N} / \mathrm{m}^{3}\right]}\end{array}$ & $\mathrm{S}_{\mathrm{NO}}$ & 4.28 & 3.99 & 3.43 & 2.91 & 2.44 \\
\hline $\begin{array}{l}\text { Free and saline ammonia } \\
{\left[\mathrm{g} \mathrm{N} / \mathrm{m}^{3}\right]}\end{array}$ & $\mathrm{S}_{\mathrm{NH}}$ & 1.36 & 0.39 & 0.17 & 0.09 & 0.06 \\
\hline $\begin{array}{l}\text { Soluble biodegradable } \\
\text { organic nitrogen }\left[\mathrm{g} \mathrm{N} / \mathrm{m}^{3} \text { ] }\right.\end{array}$ & $\mathrm{S}_{\mathrm{ND}}$ & 0.96 & 0.85 & 0.75 & 0.67 & 0.59 \\
\hline \begin{tabular}{|l|} 
Particulate biodegradable \\
organic nitrogen $\left[\mathrm{g} \mathrm{N} / \mathrm{m}^{3}\right]$
\end{tabular} & $\mathrm{X}_{\mathrm{ND}}$ & 3.45 & 3.49 & 3.58 & 3.67 & 3.76 \\
\hline $\begin{array}{l}\text { Total suspended solids } \\
{\left[\mathrm{g} \mathrm{SS} / \mathrm{m}^{3}\right]}\end{array}$ & TSS & 4604 & 4611 & 4613 & 4615 & 4616 \\
\hline \multicolumn{7}{|l|}{ Effluent } \\
\hline $\begin{array}{l}\text { Chemical oxygen demand } \\
\left.\text { [g COD } / \mathrm{m}^{3}\right]\end{array}$ & COD & 21.10 & 21.13 & 21.16 & 21.19 & 21.22 \\
\hline $\begin{array}{l}\text { Total suspended solids } \\
{\left[\mathrm{g} \mathrm{SS} / \mathrm{m}^{3}\right]}\end{array}$ & TSS & 12.21 & 12.22 & 12.23 & 12.23 & 12.24 \\
\hline $\begin{array}{l}\text { Free and saline ammonia } \\
{\left[\mathrm{g} \mathrm{N} / \mathrm{m}^{3}\right]}\end{array}$ & $\mathrm{S}_{\mathrm{NH}}$ & 1.36 & 0.39 & 0.17 & 0.09 & 0.06 \\
\hline $\begin{array}{l}\text { Nitrate and nitrite nitrogen } \\
{\left[\mathrm{g} \mathrm{N} / \mathrm{m}^{3}\right]}\end{array}$ & $\mathrm{S}_{\mathrm{NO}}$ & 4.28 & 3.99 & 3.43 & 2.91 & 2.44 \\
\hline $\begin{array}{l}\text { Organic nitrogen } \\
{\left[\mathrm{g} \mathrm{N} / \mathrm{m}^{3}\right]}\end{array}$ & Norg & 2.05 & 1.94 & 1.85 & 1.76 & 1.69 \\
\hline $\begin{array}{l}\text { Total nitrogen } \\
{\left[\mathrm{g} \mathrm{N} / \mathrm{m}^{3}\right]}\end{array}$ & $N_{\text {total }}$ & 7.70 & 6.33 & 5.44 & 4.76 & 4.19 \\
\hline $\begin{array}{l}\text { Total Kjeldahl nitrogen } \\
{\left[\mathrm{g} \mathrm{N} / \mathrm{m}^{3}\right]}\end{array}$ & TKN & 3.42 & 2.34 & 2.01 & 1.86 & 1.75 \\
\hline \multicolumn{7}{|l|}{ Return activated sludge } \\
\hline $\begin{array}{l}\text { Total suspended solids } \\
{\left[\mathrm{g} \mathrm{SS} / \mathrm{m}^{3}\right]}\end{array}$ & TSS & 12702 & 12720 & 12727 & 12732 & 12736 \\
\hline
\end{tabular}

Simulation results show that when temperature increases the concentrations of heterotrophic $\left(\mathrm{X}_{\mathrm{BH}}\right)$ and autotrophic biomass $\left(\mathrm{X}_{\mathrm{BA}}\right)$ become higher in the biodegradation tanks. This is a consequence of the maximum specific growth rate of the heterotrophic $\left(\mu_{\mathrm{H}}\right)$ and the autotrophic biomass $\left(\mu_{\mathrm{A}}\right)$ 
that are modelled by temperature dependent relationships. Due to the increase of the biomass concentration in the system the concentration of products derived from the death of microorganisms are also increased. For this reason, the concentrations of the slowly biodegradable substrate $\left(X_{S}\right)$, inert particulate substrate $\left(X_{P}\right)$ and particulate biodegradable organic nitrogen $\left(X_{N D}\right)$ increase at higher temperatures. The temperature rise favors also the anoxic and aerobic hydrolysis of $X_{S}$ into readily biodegradable substrate $\left(S_{S}\right)$. Consequently, the readily biodegradable substrate $\left(\mathrm{S}_{\mathrm{S}}\right)$ increases with the influent temperature increase. It may be also noticed that concentration of total suspended solids (TSS) in the bioreactors and in the return activated sludge increase with the influent temperature rise. The concentration of total suspended solids is increasing since the majority of the particulate components from the activated sludge process are increasing when the influent temperature gets higher. The dissolved oxygen concentration $\left(S_{0}\right)$ is influenced by the value of the dissolved oxygen saturation value that is decreasing when the temperature increases. On the other hand, dissolved oxygen concentration is also influenced by the mass transfer coefficient $K_{L} a$, as the latter increases when the temperature is higher. As a consequence, the dissolved oxygen concentration is affected by these two opposing effects of the influent temperature.

The autotrophic biomass has an important role in the nitrification process. According to the steady state simulations the autotrophic biomass is increased by $6.4 \%$ at the temperature of $22^{\circ} \mathrm{C}$ compared to the value at $10^{\circ} \mathrm{C}$ influent temperature. At increased temperature, higher amount of free and saline ammonia $\left(\mathrm{S}_{\mathrm{NH}}\right)$ are transformed into nitrites and nitrates $\left(\mathrm{S}_{\mathrm{NO}}\right)$. As a result, the $\mathrm{S}_{\mathrm{NH}}$ concentration at the outlet of the aerated zone of the bioreactors is decreasing. Likewise, the nitrification process, the denitrification is also intensified at higher temperature. This causes the increase of the eliminated nitrogen gas and results in the decrease of the $S_{N O}$ in the bioreactors. The increase of influent temperature favors the ammonification process of transforming the soluble biodegradable organic nitrogen $\left(\mathrm{S}_{\mathrm{ND}}\right)$ into $\mathrm{S}_{\mathrm{NH}}$. Therefore, the $S_{N D}$ concentration decreases at higher temperature values. The ammonification process is dependent on the ammonification rate $\left(k_{a}\right)$ and this is revealed by the developed model.

The study of the effluent stream reveals that when influent temperature increases from $10^{\circ} \mathrm{C}$ to $22^{\circ} \mathrm{C}$ the concentrations of COD and TSS are slightly increased by less than $1 \%$. All of nitrogen compounds are decreased, as total nitrogen concentration $\left(S_{\text {total }}\right)$ decreases roughly by $46 \%$, and total Kjeldahl nitrogen (TKN) by almost $49 \%$. The highest influence can be noticed at the ammonia, which decreases by nearly $96 \%$. As a general assessment, it may be stated that in the terms of nitrogen removal the wastewater treatment plant can be operated more efficiently at the higher influent temperatures of the warmer seasons. 


\section{Influent Temperature Effects - Dynamic State}

The effects of the influent wastewater temperature were investigated in dynamic state as well. Three influent temperature profiles consisting in 22 days of the different considered seasons (cold, intermediate and warm) were analyzed, according to the WWTP temperature measurements. Figure 2 presents the influent temperature profiles of this 22 days-period for the months of February, May and July.

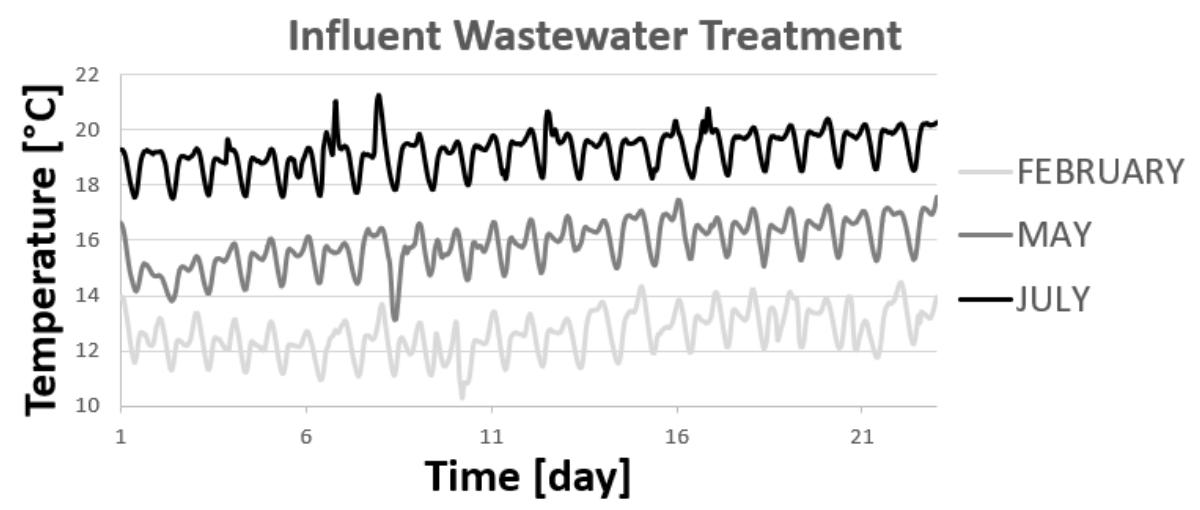

Figure 2. Time variation of the influent's temperature depending on the season (months February, May and July)

The dynamic state simulations considered variable influent temperature values, while the other influent components were considered constant. The dynamic simulations, showing the influent temperature effects on the effluent wastewater concentrations, are presented in Figure 3 for the last 18 days of the considered periods of time.

It may be observed that dyanmic results are complying with the steady state results. The concentration of COD, soluble COD and total suspended solids increase with the influent temperature increase. In the warm season the concentration of nitrogen compounds are lower due to the intensified nitrification and denitrification processes. This is a consequence of the already concluded main trend, according to which at higher temperature the growth of heterotrophs and autotrophs is intensified. It can be noticed that the variation of ammonia effluent concentration is lower at high temperatures. Due to this, in warm seasons the higher temperature may act in a favourabe way to the task of maintaining the ammonium concentration below the regulation limit. 

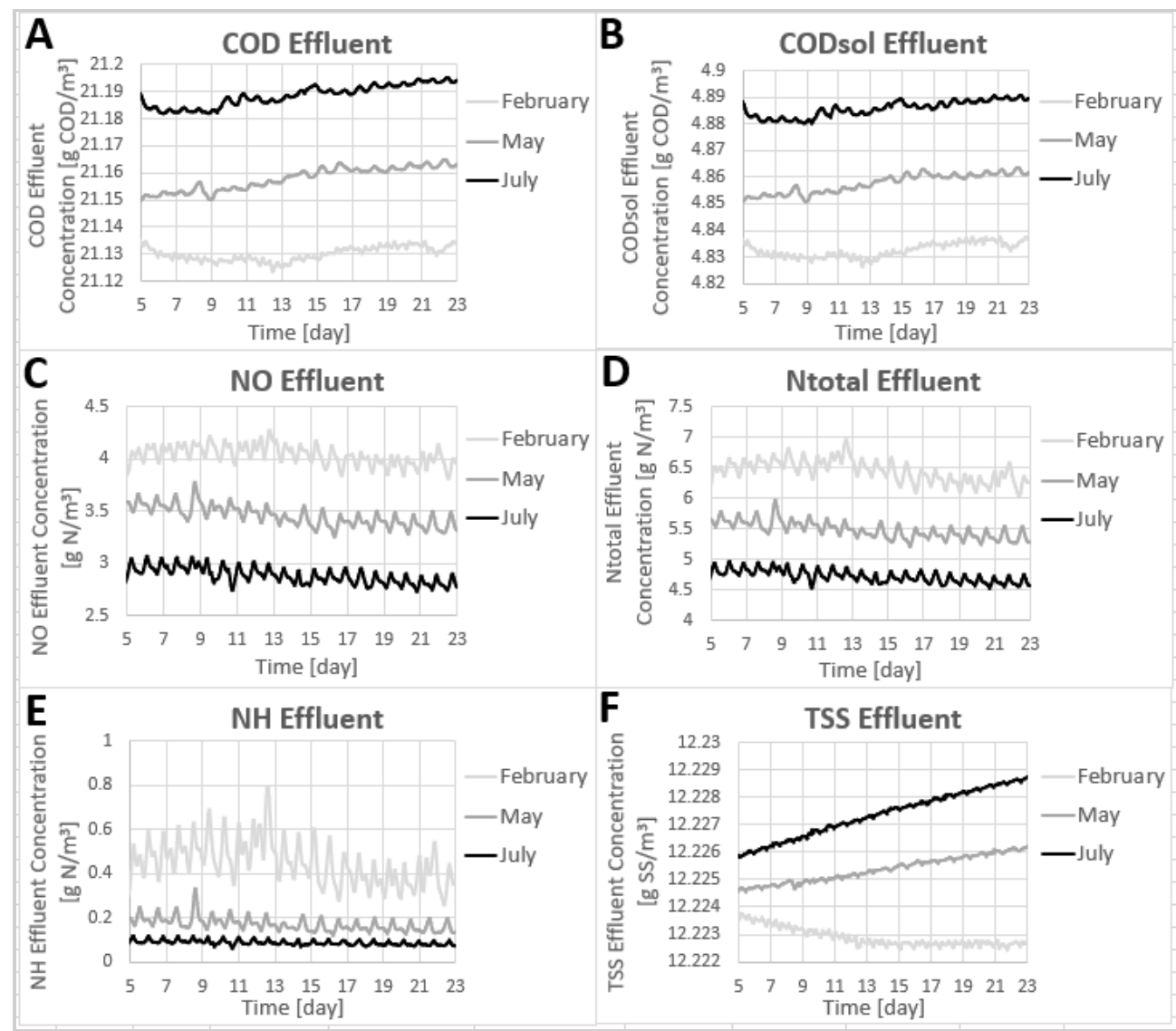

Figure 3. The influent temperature dynamic effects on the effluent concentrations, as response to the three influent temperature changing profiles: A. Total COD,

B. Soluble COD, C. Nitrates and nitrites, D. Total nitrogen, E. Ammonia, F. Total suspended solids

It might be also concluded that disturbances featuring relatively long-lasting influent temperature decrease (e.g. persistent rain or frost) may negatively affect the performance of the wastewater treatment, requesting for predictive counteracting actions that may be offered by feedforward or advanced control algorithms.

Figure 4 shows the dynamic state effect of the influent temperature on the wastewater components in the last aerated bioreactor. 


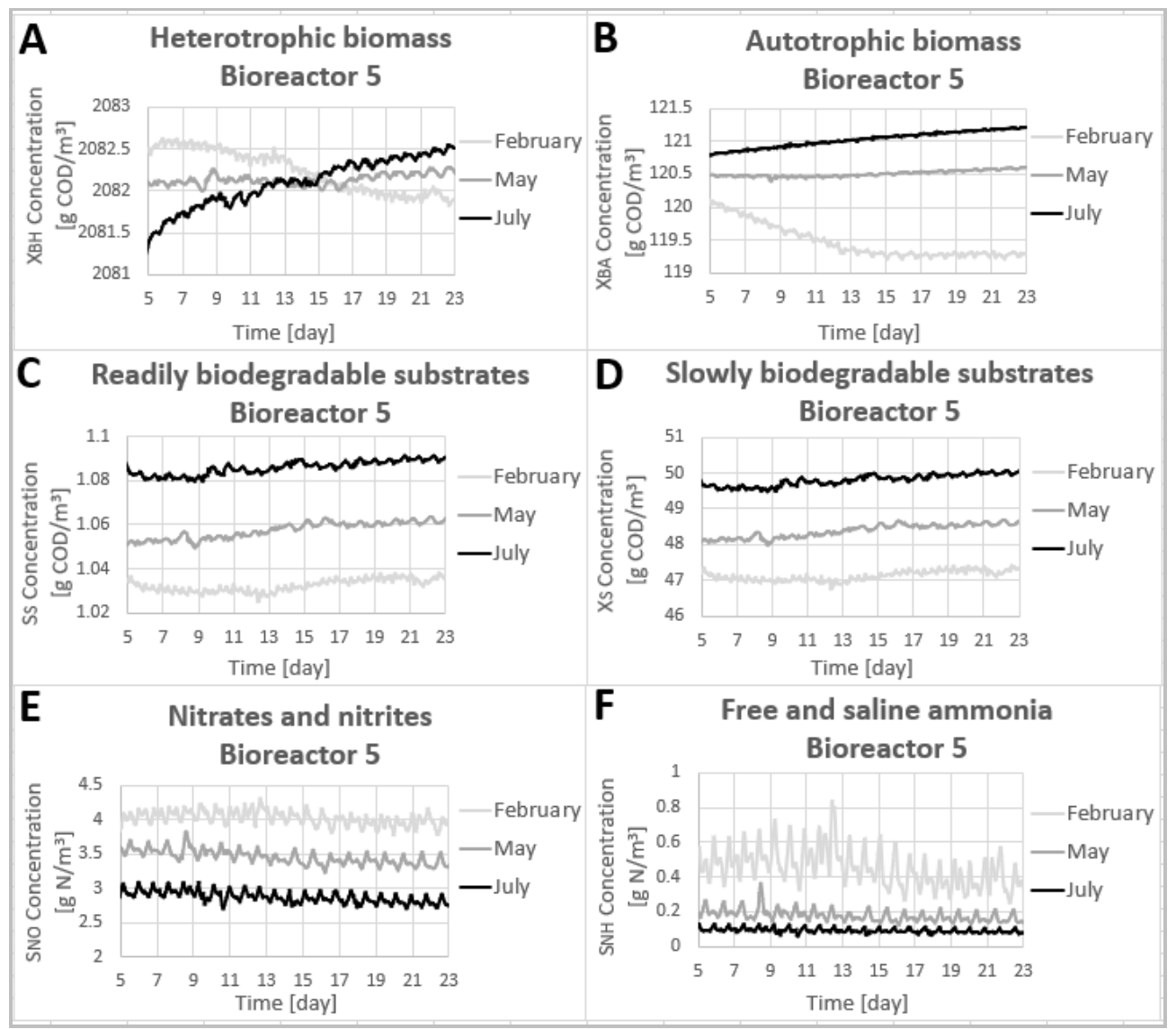

Figure 4. The influent temperature effects on the concentrations in the last aerated bioreactor, as response to the three influent temperature changing profiles:

A. Heterotrophic biomass, B. Autotrophic biomass C. Readily biodegradable substrate, D. Slowly biodegradation biomass, E. Nitrates and nitrites, F. Ammonia

It can be noted that wastewater composition changes at the outlet of the biodegradation basins are in agreement with the steday state results, i.e. high influent temperature leads to the increase of $X_{B A}, S_{S}, X_{S}$ and to the decrease of $\mathrm{S}_{\mathrm{NO}}, \mathrm{S}_{\mathrm{NH}}$. It was also observed that in the case of heterotrophic biomass concentration, short-term and long-term influent temperature efects are changing with time. This behaviour may be attributed to the fact that $\mathrm{X}_{\mathrm{BH}}$ concentration is influenced by the two counteracting dynamic effects on the dissolved oxygen concentration, having associated different time constants. 


\section{CONCLUSIONS}

The study of the influent wastewater temperature effects on wastewater quality was performed both in steady and dynamic state. Based on a calibrated WWTP simulator three different temperature profiles corresponding to the cold, intermediate and warm seasons were considered. It was shown that the increase of the influent temperature leads to the slowly increase of the COD and TSS concentrations in the effluent, respectively to the decrease of the nitrogen components in the effluent and activated sludge system. Investigating the nitrogen removal and specifically the ammonia oxidation to nitrates, the higher temperatures are the most favorable for plant operation with desired performance. It was observed that short-time variations in the influent temperature do not have a strong effect on the effluent concentrations, but the long-time, persistent ones may have important consequences. These effects were quantitatively assessed.

The perspectives of using this research results are showing promising applications. Based on the calibrated simulator that includes the temperature impact, the operation of the WWTP may be improved by the revealed predictions of the influent temperature effects. They are necessary for the application of feedforward or model predictive control system implementation and may directly integrate the weather forecast as estimated disturbance. Additionally, assessment of the influent temperature effects on the WWTP performance may be used to the design of the heat exchanger network aimed to recover heat from the sewage system originating wastewater.

\section{EXPERIMENTAL SECTION}

MATLAB software and the Simulink graphical programming extension were used in the present research. The developed simulator is based on the Benchmark Simulation Model provided by COST Action 682 and the IWA Working Group on Assessment of Control Strategies for Wastewater Treatment Plants. The equations of the bioreactors model and the primary and secondary clarifier equations are written in $\mathrm{C}$ programming language. To reduce simulation time and preserve computing resources, the codes have been compiled and incorporated into the Simulink environment by S-Function blocks. Simulink ODE15s numerical solving algorithm were used to solve the set of differential and algebraic equations of the model. 


\section{REFERENCES}

1. C. Martin, P.A. Vanrolleghem, Environmental Modelling \& Software, 2014, 60, 188

2. M.H. Gerardi, "Nitrification and Denitrification in the Activated Sludge Process", A. John Wiley \& Sons Inc. Publication, New York, 2002.

3. G.S. Ostace, V.M. Cristea, P.S. Agachi, Environmental Engineering and Management Journal, 2012, 11, 147.

4. M. Várhelyi, M. Brehar, V.M. Cristea, "Control strategies for wastewater treatment plants aimed to improve nutrient removal and to reduce aeration costs", paper presented at the 2018 IEEE International Conference on Automation, Quality and Testing, Robotics, AQTR 2018 - THETA 21st Edition, Proceedings, 2018, 1-6.

5. A. Nair, V.M. Cristea, P.S. Agachi, M. Brehar, Water and Environmental Journal, 2018, 32, 164.

6. X. Wang, H. Ratnaweera, J.A. Holm, V. Olsbu, Journal of Environmental Management, 2017, 193, 1.

7. S. Balku, Celal Bayar University Journal of Science, 2018, 14, 77.

8. O. Wanner, V. Panagiotidis, P. Clavadetscher, H. Siegrist, Water Research, 2005, 39, 4725.

9. J.B. Copp (ed.), "The COST Simulation Benchmark: Description and Simulator Manual", Office for Official Publications of the European Communities, European Commission. Directorate-General for Research COST Action 624, Luxembourg, 2002.

10. M. Henze, W. Gujer, T. Mino, M.C.M. van Loosdrecht, "Activated Sludge Models: ASM1, ASM2, ASM2d and ASM3", Scientific and Technical Report, IWA Publishing, London, 2000.

11. I. Takács, G.G. Patry, D. Nolasco, Water Research, 1991, 25, 1263. 
